http://www.jfas.info

\title{
COMPARISON BETWEEN MPC AND PID CONTROL FOR COMPACT HYDRO DISTILLATION PROCESS
}

\author{
N. N. Mohammad, A. A. Azman, M. H. Marzaki, R. Adnan, N. Ismail and M. H. F. Rahiman*
}

Faculty of Electrical Engineering, Universiti Teknologi MARA, 40450 Shah Alam, Malaysia

Published online: 05 October 2017

\begin{abstract}
This paper presents water temperature of a hydro distillation that have been modelled by using linear ARX Modal. Based on the modal obtained, a model predictive controller and PID controller have been developed. Both controller undergone the performance of controller tests that includes set point, set point change and load disturbance. The aim of those three performance tests are to test the robustness among those controllers. In this study, the comparative of the controller performances were evaluated and analyzed via simulation. The criteria of transient responses which are rise time, settling time and percentage of overshoot is chosen to evaluate the robustness of the controller performance. The simulation result shows that the better performance of overall robustness test have been conquered by MPC with compared to PIDCC and PIDZN.
\end{abstract}

Keywords: ARX model; system identification; model predictive controller; PID controller.

Author Correspondence, e-mail: hezrif@ieee.org

doi: http://dx.doi.org/10.4314/jfas.v9i4s.5

\section{INTRODUCTION}

Nowadays, there is a resurgence that involves in the field of essential oil. Essential oil have great interest not only in academia but also potentially in the industry area. It is because its 
offers various application for example in perfumery, food industry, aromatherapy, pharmaceuticals and cosmetics [1-2]. Extraction process is one method of having an essential oil whereas it separates the volatile compound from the aromatic plant. Essential oil can be obtained by various form of extraction techniques such as steam distillation, hydro distillation, supercritical fluid extraction, microwave extraction and others [3]. Although hydro distillation is a conventional technique, but it is still applicable and been used in industrial scale because it is simple, selectivity and inexpensive [4-5].

There are several factors that effecting the quality and quantity in essential oil. These factors are temperature, pressure, distillation time, chemical composition and particle size of raw material [6]. Nevertheless, temperature contributes the most significant effect to the quality and the output yield [7-9]. Therefore, monitoring temperature control is the most important in extraction process and it is selected to be process variable in this study. Almost conventional method like hydro distillation are not control at all. In addition, hydro distillation process are sensitive towards parameter changes. Therefore, proper control scheme have been implemented in order to overcome the problem and also to improve the performances of hydro distillation process.

Process models is necessary which it can take various forms depend on their intended application as well as many controller design algorithm need such models. In performing the controller design, process model is crucial as it is fundamental step to have an efficient model process that represent the behaviour of system dynamic [10]. Application of system identification can be seen to have vast development in control systems and mathematics [11, 32-33]. Until today, the system identification still preferable and be used as a technique to mimic the process dynamic of the system that can be formulated by having an input-output data [11-12]. Therefore, it is very important to have good model structure and model parameter in order to define the process. In this study, linear model structure has been developed by using system identification approached. An ARX (Autoregressive with external input) model structure has been employed to model the hydro distillation system. Then, the ARX model obtained is extensively used for designing a controller.

Model Predictive Control (MPC) can be classified as an advanced control strategies that has been introduced in 1970s. Although this control technique was precipitated a few decades ago, however its developments have receive active attention in robotics application [13-15], 
process control [16-20] and pilot distillation column [21-23]. MPC is widely been used because its offer efficient control strategy that can capture the dynamic system and also can improve the process control. In the words, MPC method describing the system dynamic over a specific time slot and applies optimal control actions to the system. Moreover, the unique of this control strategy which it have an efficient in handling the system constraints and it updated the changes of the process parameter [24-25]. According to [26], MPC have been developed as a controller in regulating the steam temperature of pilot plant that can maintain at the optimum temperature in order to achieve better response.

Unlike PID controller, this controller is not effectively control the system with large constraints [27]. Besides that, the system performance of PID controller highly depends on three terms that required to be tuned which makes the tuning of PID controller is a challenging task [28]. Therefore, in this study, the implementation of MPC is used to improve the performances that based on set point, set point change and load disturbance with compared to PID controller.

\section{HYDRO DISTILLATION POT}

In this study, hydro distillation pot was carried out that is located at Distributed Control System Laboratory in Universiti Teknologi MARA, Shah Alam. The hydro distillation system shown in Fig. 1 contains steel distillation tank, temperature sensor which is (RTD PT100) that placed at the bottom of the plant to measure water temperature, hot plate as heating element and condenser as to condensed the hot vapour. Fig. 2 depicts the real diagram of hydro distillation system that intended to extract the essential oil. In hydro distillation technique, the raw material was fully submerged in the water. An experiment has been carried out from room temperature until it reaches to steady state temperature. During operation, water that had been heated from the hot plate will boil the water until the vapour from hot water passes through the condenser before it drops into a collecting container. The sampling period for the water temperature was sampled at one second. MATLAB version R2015a been used in collecting and recording the data during experiment. 


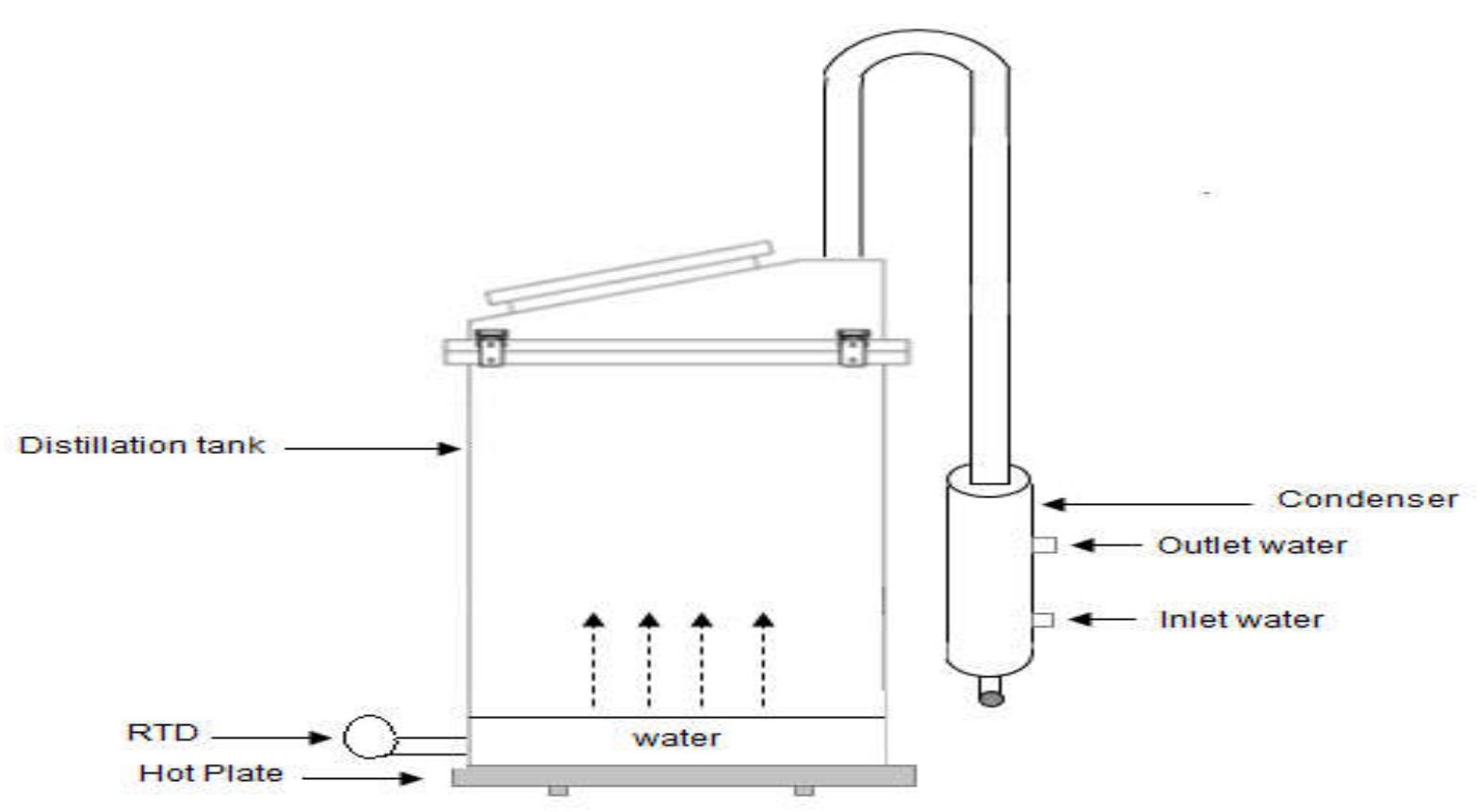

Fig.1. Diagram of the hydro distillation process

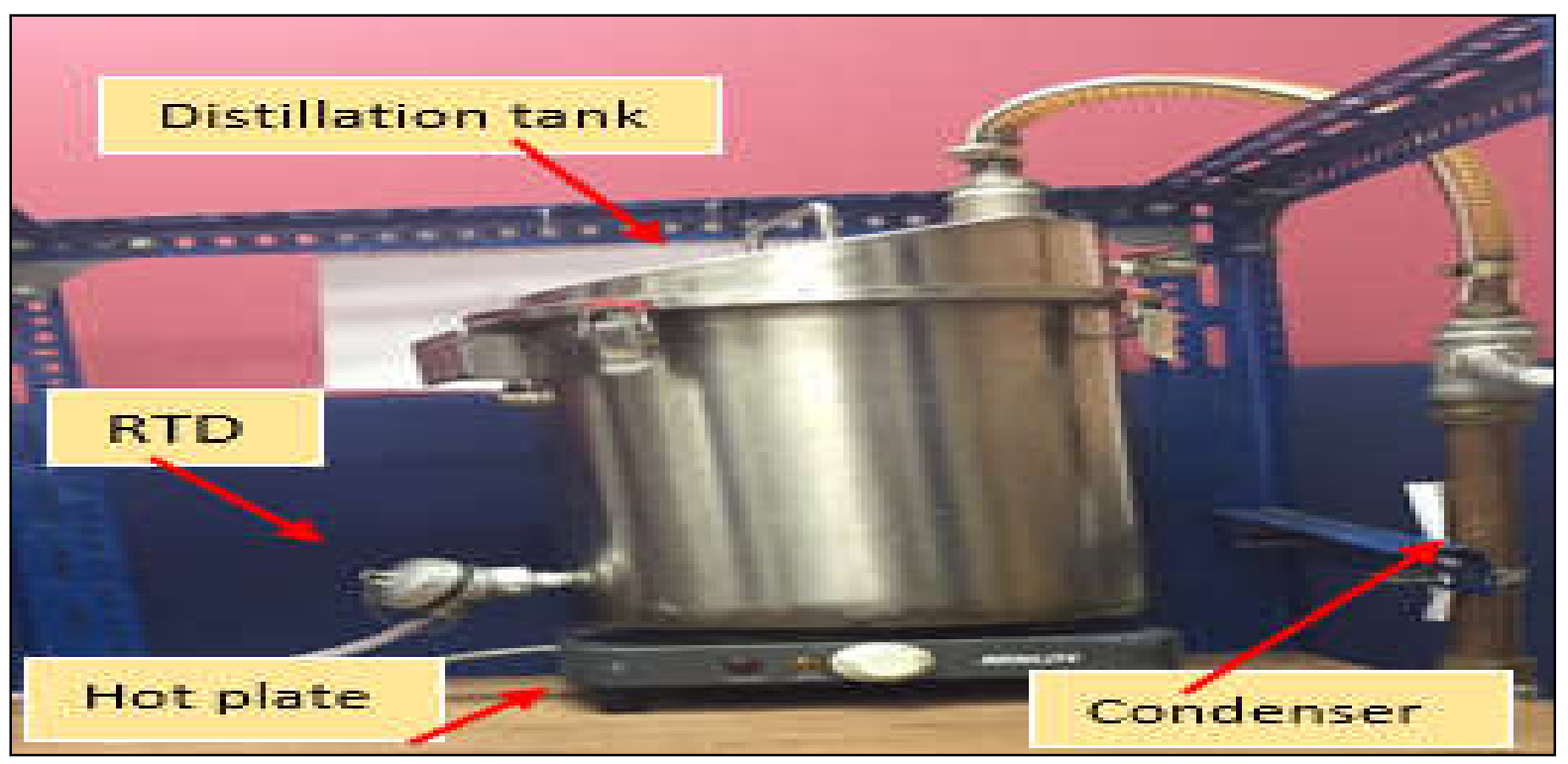

Fig.2. Diagram of the hydro distillation system

\section{SYSTEM IDENTIFICATION}

System identification is one of the techniques in determining a mathematical model of the system. It can be represented the behaviour of process dynamic of an actual plant. Usually, the model structure involves input-output data of the system. The modelling strategy will start with several experiments in obtaining input-output data, complied by model structure selection, model estimation and model validation. Then, the model structure is needed in 
designing and performing for controller approaches.

\subsection{ARX Model}

In this study, ARX model structure as shown in Fig. 3 has been developed by using input-output data that have been collected from the experiment. Generally, the ARX model can be expressed by:

$\mathrm{A}(\mathrm{q}) \mathrm{y}(\mathrm{t})=\mathrm{B}(\mathrm{q}) \mathrm{u}(\mathrm{t})+\mathrm{e}(\mathrm{t})$

where $A(q)$ and $B(q)$ are given by

$A(q)=1+a_{1} q^{-1}+\cdots+a_{n a} q^{-n a}$

$B(q)=b_{o}+b_{1} q^{-1}+\cdots+b_{n b} q^{-n b}$

From Equation (2) and (3), $\mathrm{A}(\mathrm{q})$ and $\mathrm{B}(\mathrm{q})$ as system dynamic and $\mathrm{q}^{-1}$ called as time shift operator and the variable of $a_{1 . . n a}$ and $b_{1 . . n b}$ are parameter to be estimated. The $q$ description shown is equivalent to the Z-transform [9].

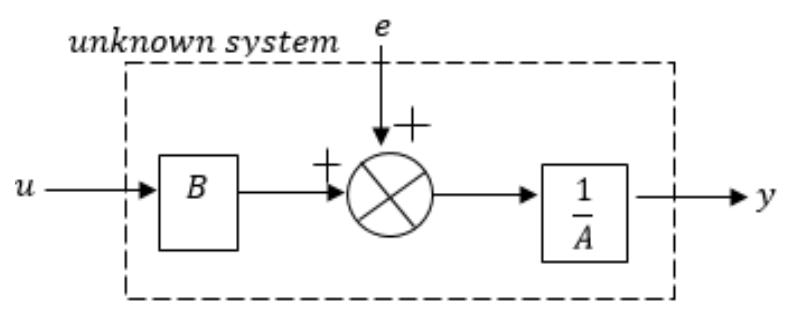

Fig.3. ARX model structure

\subsection{Model Estimation}

The objective of model estimation is used to estimate the parameters vector, $\theta$ of the model. In this work, the prediction error method been used in estimating the parameter that represented by:

$\varepsilon(t, \theta)=y(t)-\hat{y}(t \mid \theta)$

From Equation (4), $y(t)$ is known as measured output, $\hat{y}(t \mid \theta)$ is the predicted output and $\theta$ is the estimated parameter. Generally, the prediction error can be measured by using:

$V_{N}\left(\theta, Z^{N}\right)=\frac{1}{2 N} \sum_{t=1}^{N} \varepsilon^{2}(t, \theta)$

where $Z^{N}$ referred to the estimation dataset. In equation (5), $V_{N}$ or known as loss function used Levenberg-Marquardt algorithm as the minimizing technique which it interpolates between Gauss-Newton and gradient-descent method.

\subsection{Model Validation}

Model validation is the part where it is the crucial step in the model building sequence.in the model building sequence. It is used to verify the model whether the model can satisfy under 
the modelling requirement or next can be used in further application. Often, the validation of a model be based on 1-SAP. The accuracy of this method identify either the model is accepted or be rejected. Besides that, coefficient of determination, $\mathrm{R}^{2}$ or known as model fitting is another method to verify the model whether is good model or not. $\mathrm{R}^{2}$ shows the narrowly between predicted output and the measured output.

\section{MODEL PREDICTIVE CONTROL}

Today, Model Predictive Controller (MPC) based control strategy is widely been used among the industrial and in dynamical system since this controller can anticipate the future response of a given plant. The main purpose of MPC control method is, it can predict the dynamic system over a specific time slot using a system model and computes optimal control action by minimizing a cost function as in Fig. 4 [29]. There are three steps involve in the MPC procedure which are cost function optimization, future state/output prediction and control signal. Fig. 5 shown the basic structure of MPC. The model of the process is the main part which the formulation take place that generates the future state or the prediction output until instant of time. The applied of optimizer block that depends on cost function and constraints is used to generate the control signal implementation and then will fed to process model. The discrete time state of linear dynamic system can be defined as:

$x(k+1)=A x(k)+B u(k)$

$y(k)=C x(k)$

where $x$ state variable, $\mathrm{u}$ is control input and $\mathrm{y}$ is the performance output, $\mathrm{A}, \mathrm{B}$ and $\mathrm{C}$ are the matrices.

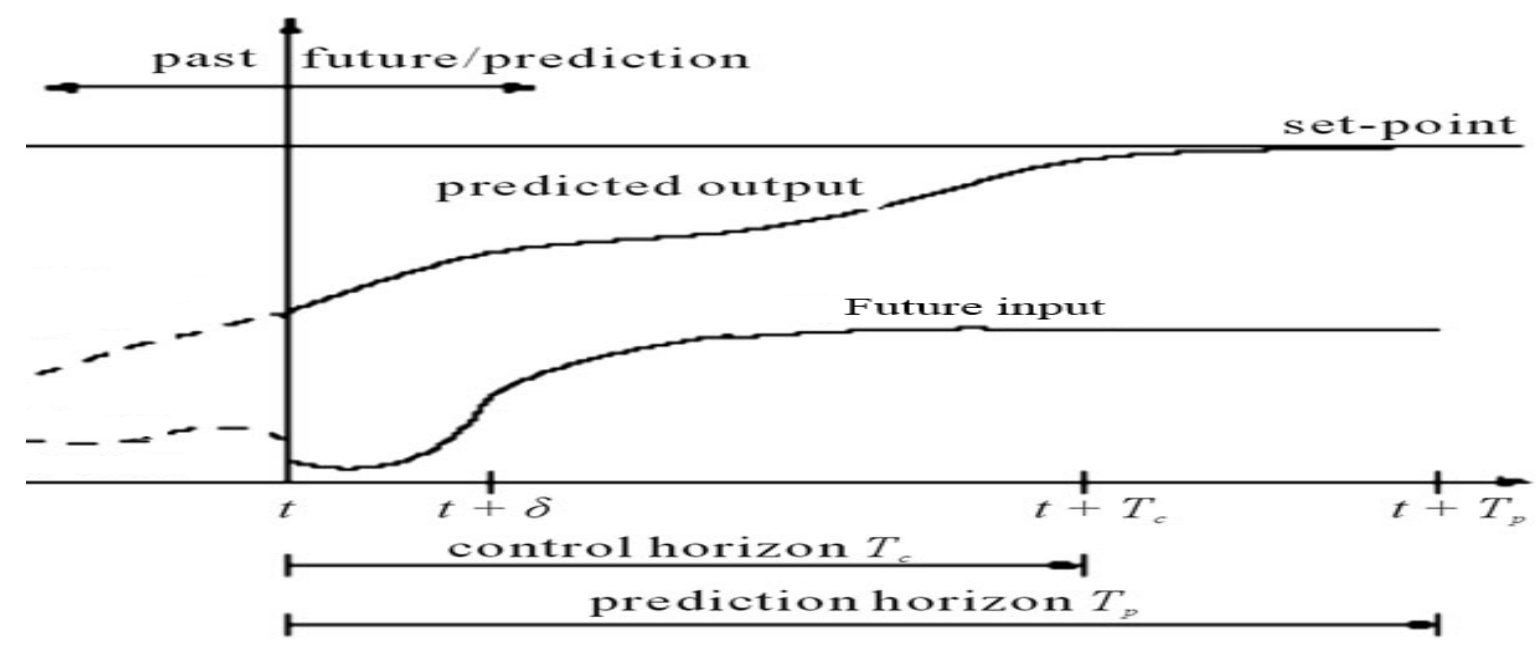

Fig.4. MPC control strategy 


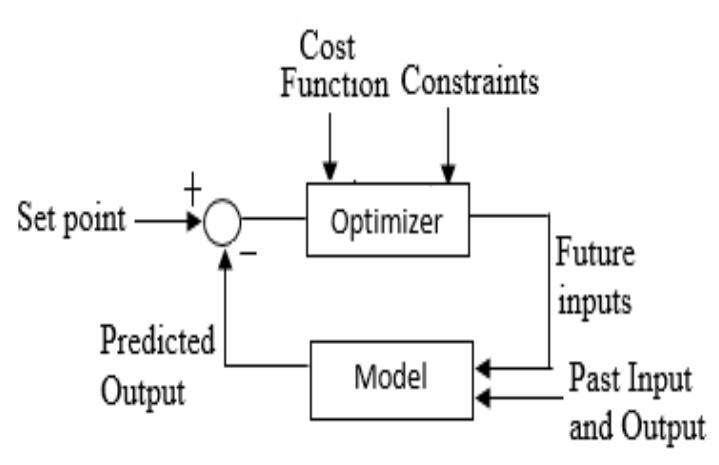

Fig.5. Block diagram of MPC

The cost function of the MPC structure can be expressed as:

$J=\left(R_{S}-Y\right)^{T}\left(R_{S}-Y\right)+\Delta U^{T} \bar{R} \Delta U$

where

$R_{S}=\left[\begin{array}{llll}1 & 1 & \cdots & 1\end{array}\right]_{1 \times N_{p}} \times r\left(k_{i}\right)$,

$r\left(k_{i}\right)$ is the reference signal at the time $k_{i}$ and $N_{p}$ is prediction horizon.

$Y=\left[\begin{array}{llll}y\left(k_{i}+1 \mid k_{i}\right) & y\left(k_{i}+2 \mid k_{i}\right) & \cdots & y\left(k_{i}+N_{p} \mid k_{i}\right.\end{array}\right]^{T}$

where $y\left(k_{i}+j \mid k_{i}\right)$ is the predicted output of model at time $k_{i}+j$ given the output at the time $k_{i}$

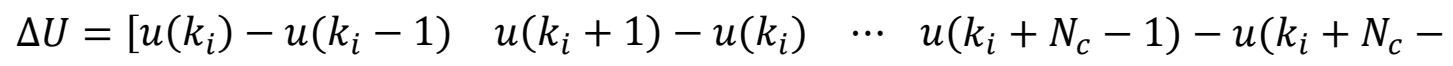

2) $T$

where $u\left(k_{i}+j\right)$ is the control parameter and $N_{c}$ is control horizon and $\bar{R}$ is tuning parameter.

\section{PID CONTROLLER}

PID controller made up from the combination of three terms (proportional, integral and derivative) that can be expressed in Equation (12). The function of integral gain is to improve in eliminating the steady state error while derivative gain is responsible in predicting future that based on the current rate of change. PID controller also refers as the controller parameter tuning process because in each mode their gain need to be tuned to satisfy the desired response. The tuning parameter must be appropriate value, since the effectiveness of the response really depends on those tuned parameter. Therefore, proper methodology for tuning parameter is necessary in order to achieve the best response. Here, Ziegler Nichols and Cohen Coon have been used as tuning approached as they are still popular control method among 
others [30]. Table 1 shown the formula for PID controller tuning for each parameters.

$u(t)=K_{p} e(t)+K_{i} \int e(t) d t+K_{d} \frac{d e(t)}{d t}$

where $\mathrm{K}_{\mathrm{p}}=$ Proportional gain, $\mathrm{K}_{\mathrm{i}}=$ Integral gain, $\mathrm{Kd}=$ Derivative gain and $\mathrm{e}(\mathrm{t})=$ error present in controller.

Table 1. Formula for PID controller tuning

\begin{tabular}{cccc}
\hline PID & Proportional & Integral Time & Derivative Time \\
Tuning & Gain, $K_{\mathrm{p}}$ & Constant, Ti & Constant, Td \\
\hline ZN & $\left(\frac{1.2}{K}\right)\left(\frac{\tau}{\theta}\right)$ & $2.0 \theta$ & $0.5 \theta$ \\
CC & $\frac{\tau}{K \theta}\left(\frac{4}{3}+\frac{\theta}{4}\right)$ & $\theta\left(\frac{32+6 \theta / \tau}{13+8 \theta / \tau}\right)$ & $\theta\left(\frac{4}{11+2 \theta / \tau}\right)$ \\
\hline
\end{tabular}

\section{RESULTS AND DISCUSSION}

\subsection{ARX Model}

Before implementing the control design, the process modal must be obtained. In this study, the input and output data that have been collected were used to model the behaviour of hydro distillation process. The both input and output data are consist of 9000 samples that shown in Fig. 6. Each of the data have been separated between testing and training by using interlacing technique. Then, the system identification approaches has been implemented to obtain the ARX model. The parameters of the modal are clearly determined which the model order is equal to 1 . Here, the discrete ARX Model can be expressed by:

$\frac{B(z)}{A(z)}=\frac{0.0286 z^{-1}}{1-0.998 z^{-1}}$
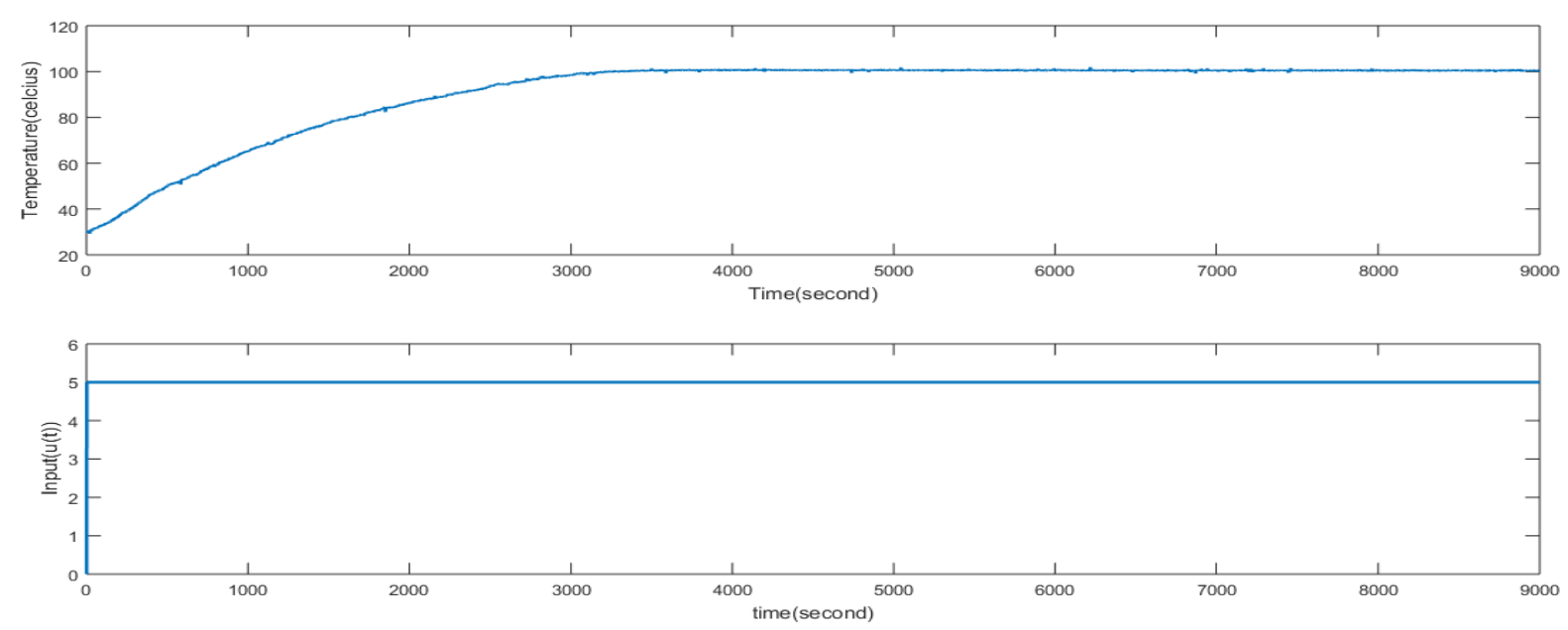

Fig.6. The temperature output response and input signal 


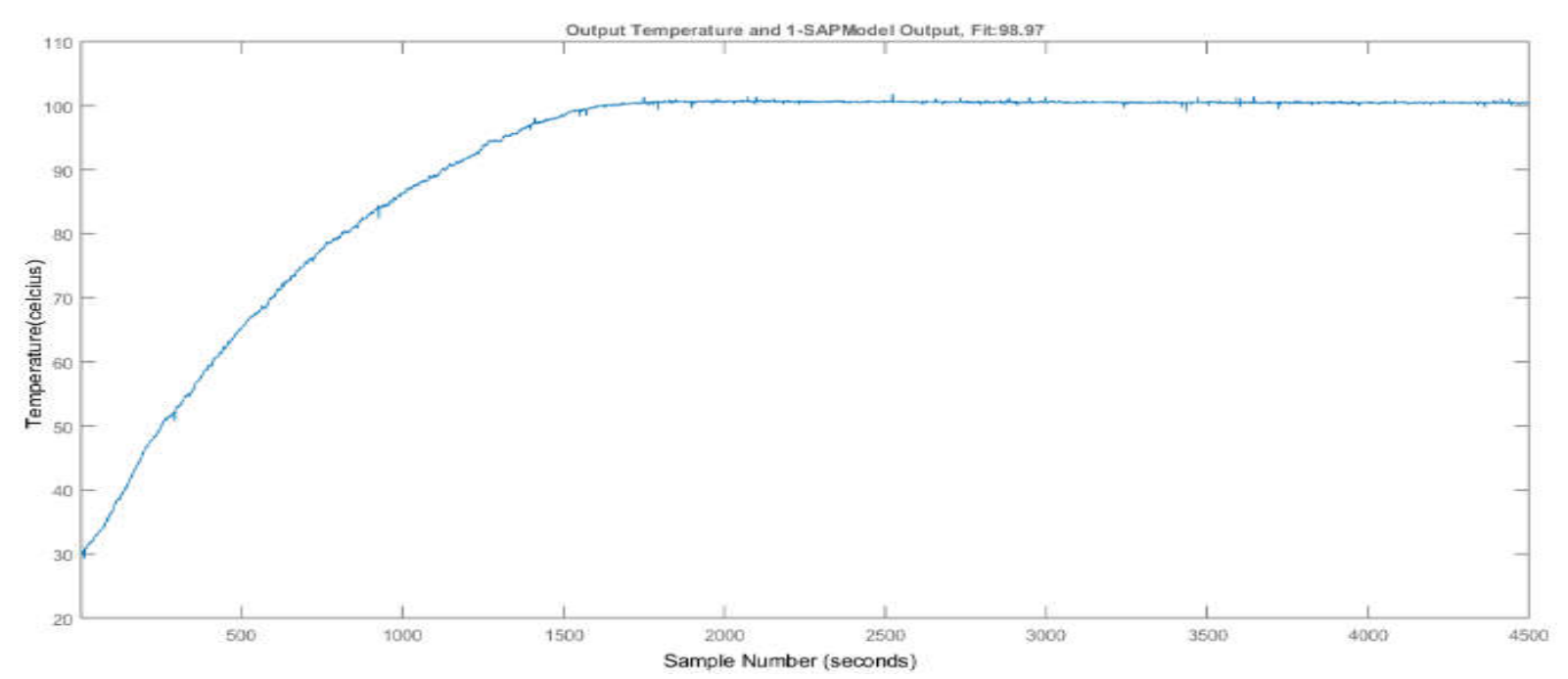

Fig.7. Output temperature by 1-SAP
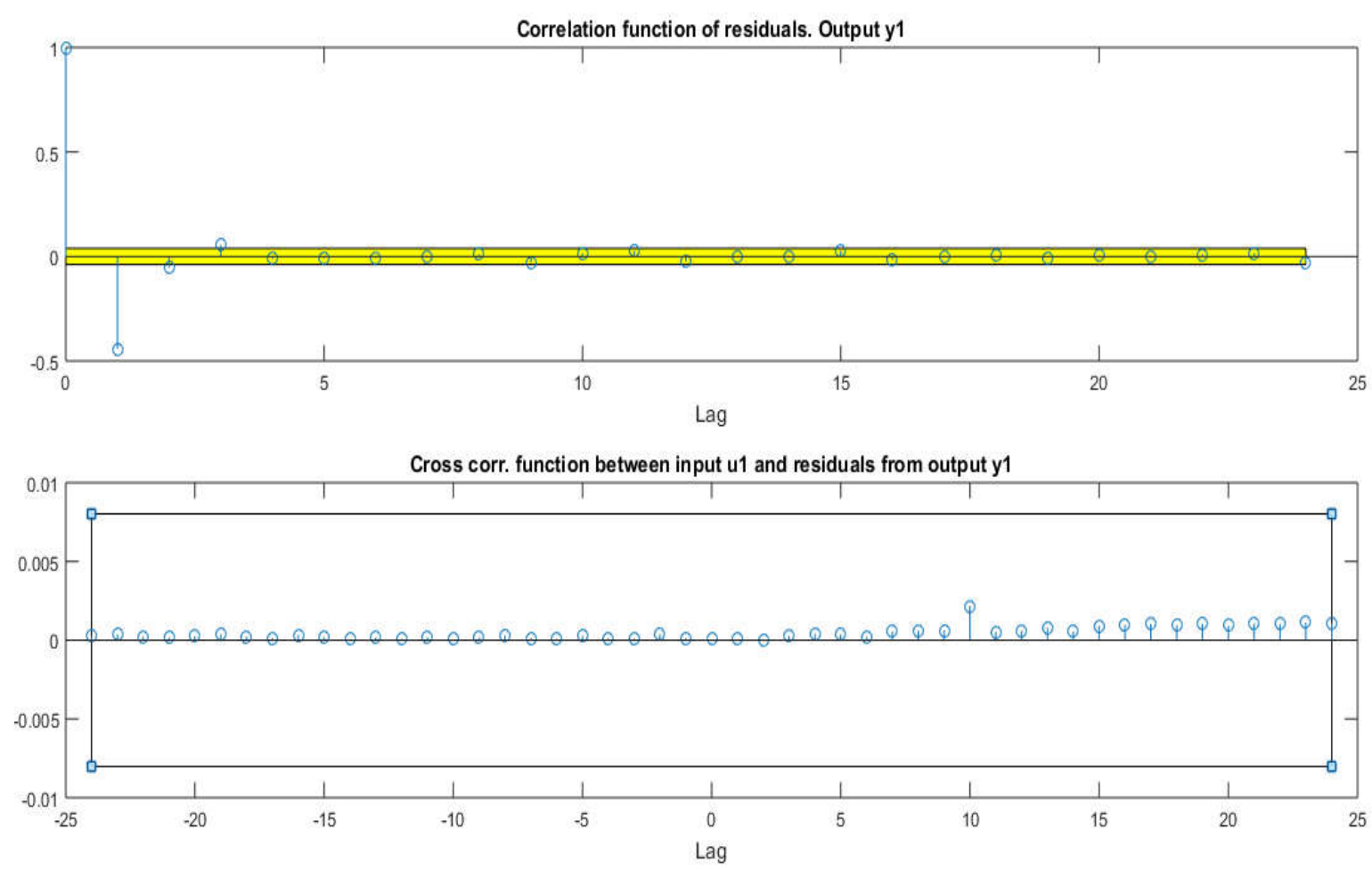

Fig.8. Residual and correlation test

Fig. 7 depicts the result of 1-SAP of model output and Fig. 8 shows the result of residual coupled with correlation test respectively. From the result obtained, the ARX model able to describe the behaviour of the hydro distillation process satisfactory with the percentage of best fit accuracy is $98.97 \%$. Based on Fig. 8, the residual result show that it has good agreement between measured output and predicted output. Moreover, the result of CCF shows the correlation between input signal and residual gives good result since the correlation coefficient lies within $95 \%$ of confidence limit. From the result of modelling, it can be 
concluded that the discrete ARX model can be accepted and be performed for designing the controller.

\subsection{Comparison Result of MPC and PID Controller}

From the ARX model obtained, the modal presented the behaviour of the hydro distillation process which it used for designing the controller. In this part, the performance comparison of MPC and PID controller were based on set point, set point change and disturbance load. The comparison have been made that based on transient response analysis which includes rise time $\left(\mathrm{T}_{\mathrm{r}}\right)$, settling time $\left(\mathrm{T}_{\mathrm{s}}\right)$ and percentage of overshoot. Here, PID controller denotes as PIDZN that using Ziegler Nichols approached and PIDCC which using Cohen-Coon approached and followed by MPC. The result of performance comparison of those controller were illustrated as in Fig. 9, Fig. 10 and Fig. 11.

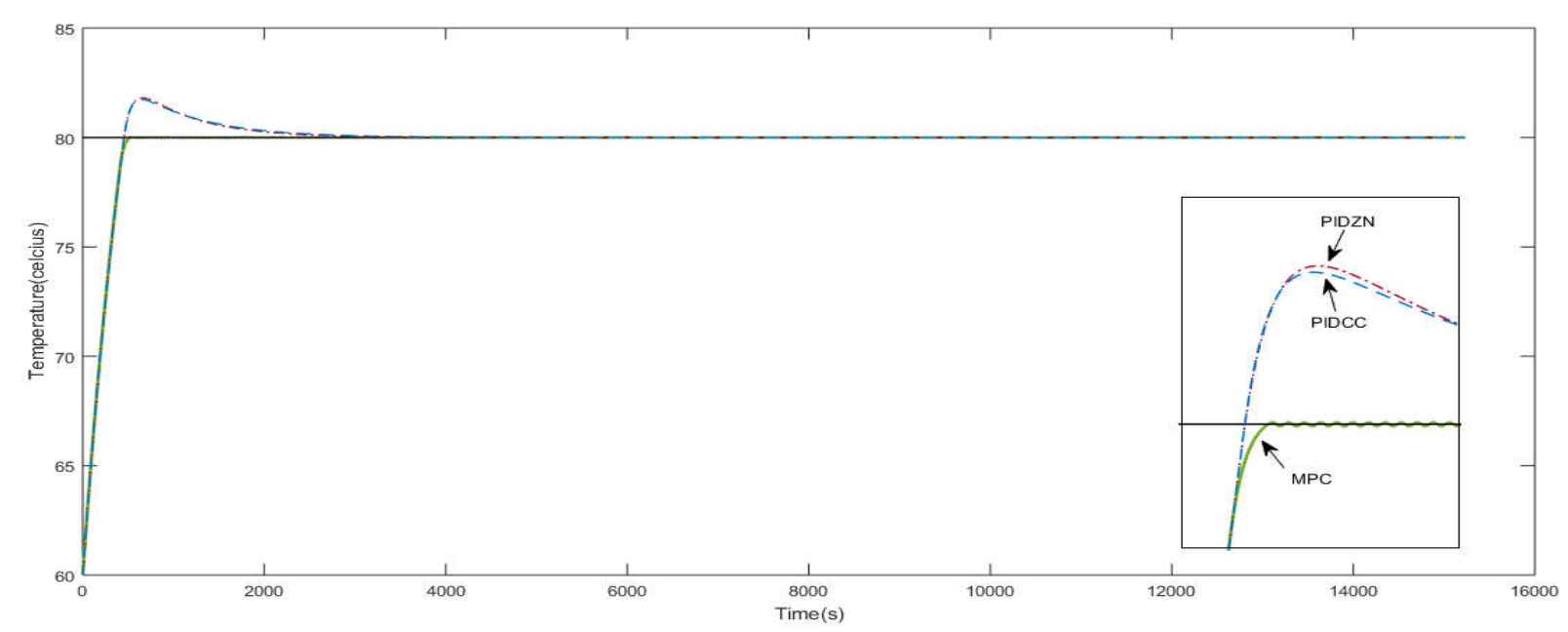

Fig.9. Performance controller for set point test

Table 2. Performance of controller for set point test

\begin{tabular}{cccc}
\hline Controller & \multicolumn{3}{c}{ Criteria of Transient Response } \\
& Rise Time, $\mathbf{T}_{\mathbf{r}}(\mathbf{s})$ & Settling Time, $\mathbf{T}_{\mathbf{s}}(\mathbf{s})$ & Percentage of Overshoot (\%) \\
\hline PIDZN & 359 & 1725 & 2.259 \\
PIDCC & 359 & 1821 & 2.168 \\
MPC & 339 & 459 & 0 \\
\hline
\end{tabular}

*The highlighted boxes shows best responses

Fig. 9 depicts the performance response of those controller for set point test. Table 2 tabulated the result of controller performance for set point test. In this experiment, the set point was set at $80^{\circ} \mathrm{C}$. From the result obtained, it clearly shows that MPC have achieved satisfactory result among the others. It can be seen that MPC have no overshoot compared to PIDZN and PIDCC, which experienced large overshoot at almost up to $2 \%$. It clearly indicated PIDZN 
have higher overshoot compared to PIDCC, which difference about $0.091 \%$. In term of rise time, PIDCC and PIDZN had same responses unlike MPC that spend much faster which is about 20s differ. Furthermore, for settling time, MPC takes shorter time compared with PIDZN and PIDCC which the difference are about 1266s and 1362s respectively.

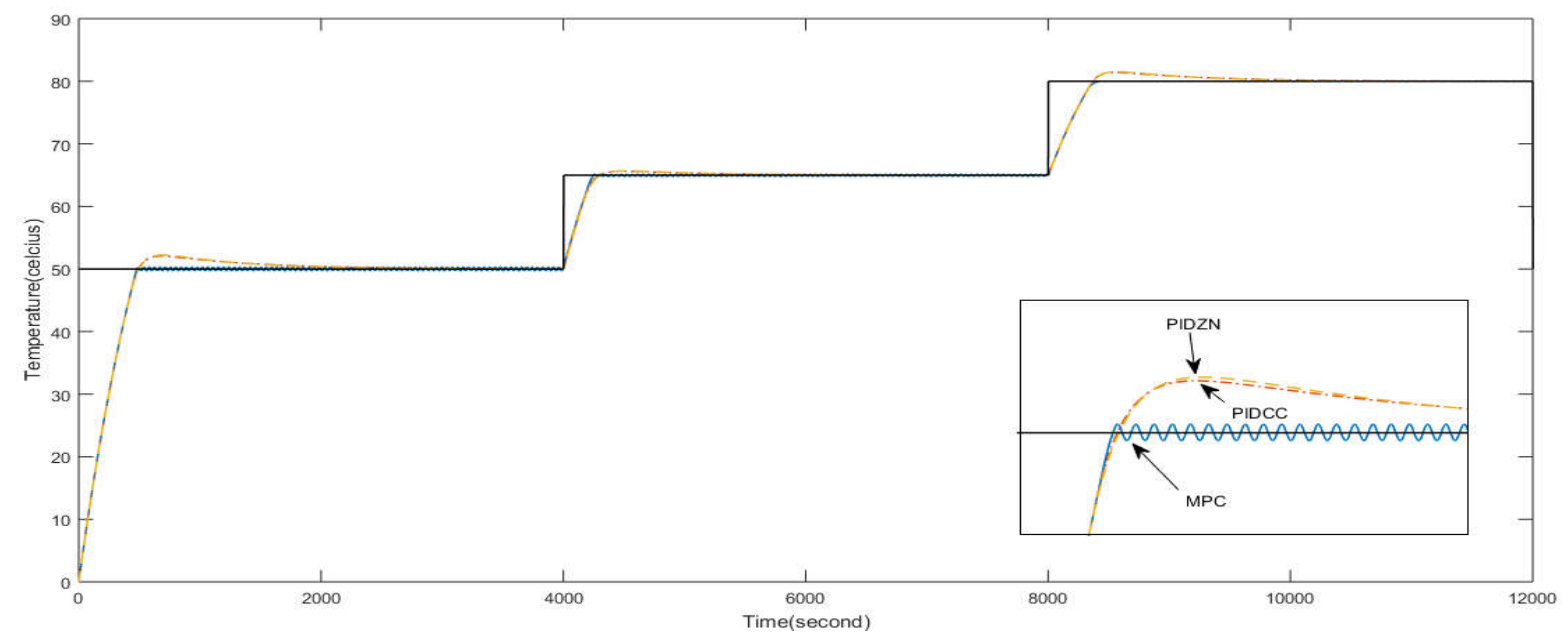

Fig.10. Performance controller for set point change

Table 3. Performance of controller for set point change test

\begin{tabular}{ccccc}
\hline Criteria of Transient Response & \multicolumn{3}{c}{ Controllers } \\
& & MPC & PIDZN & PIDCC \\
\hline \multirow{2}{*}{ Rise Time, $\mathrm{T}_{\mathrm{r}}(\mathrm{s})$} & $50^{\circ} \mathrm{C}$ & 379 & 377 & 377 \\
& $65^{\circ} \mathrm{C}$ & 189 & 205 & 200 \\
& $80^{\circ} \mathrm{C}$ & 291 & 289 & 290 \\
& $50^{\circ} \mathrm{C}$ & 468 & 1296 & 1286 \\
Settling Time, $\mathrm{T}_{\mathrm{s}}(\mathrm{s})$ & $65^{\circ} \mathrm{C}$ & 238 & 1130 & 1132 \\
& $80^{\circ} \mathrm{C}$ & 381 & 1697 & 1758 \\
& $50^{\circ} \mathrm{C}$ & 0.268 & 4.406 & 4.093 \\
& $65^{\circ} \mathrm{C}$ & 0.284 & 1.055 & 0.970 \\
\hline \multirow{2}{*}{ Percentage of Overshoot $(\%)$} & $80^{\circ} \mathrm{C}$ & 0.006 & 1.899 & 1.748 \\
\hline
\end{tabular}

*The highlighted boxes shows best response

Fig. 10 illustrates the performance of those controllers for the set point change test. The stage of the set point be set at $50^{\circ} \mathrm{C}, 65^{\circ} \mathrm{C}$ and $80^{\circ} \mathrm{C}$. The test have been done in order to indicate the ability of those controller whether each controllers able to comply the different set point change. Table 3 tabulated the result of controller performance for set point change. In term of rise time, it can be seen that at temperature of $50^{\circ} \mathrm{C}$, PIDZN and PIDCC have same response which is $377 \mathrm{~s}$ that only spend $2 \mathrm{~s}$ faster than MPC. However, at $65^{\circ} \mathrm{C}$, MPC can cater the set 
point change compared to both PID controller. The difference is about $16 \mathrm{~s}$ and $11 \mathrm{~s}$ for PIDZN and PIDCC respectively. At $80^{\circ} \mathrm{C}$, PIDZN experienced slightly faster in rise time than PIDCC and MPC which differ only about $1 \mathrm{~s}$ and 2 s respectively.

According to the result obtained when it goes to settling time criteria, MPC can complied all the set point range. It clearly showed that MPC managed to reduce the settling time about 2.7 times compared to both PID controllers at $50^{\circ} \mathrm{C}$, about 4.7 times compared to PIDZN and PIDCC at temperature of $65^{\circ} \mathrm{C}$ and about 4.45 times for PIDZN and 4.61 for PIDCC at $80^{\circ} \mathrm{C}$. On percentage of overshoot result, it showed that MPC have superior performance in this criteria when it experienced the lowest of overshoot at overall temperature set point change compared to both PID controller. PIDCC produces lower overshoot compared to PIDZN at all set point change.

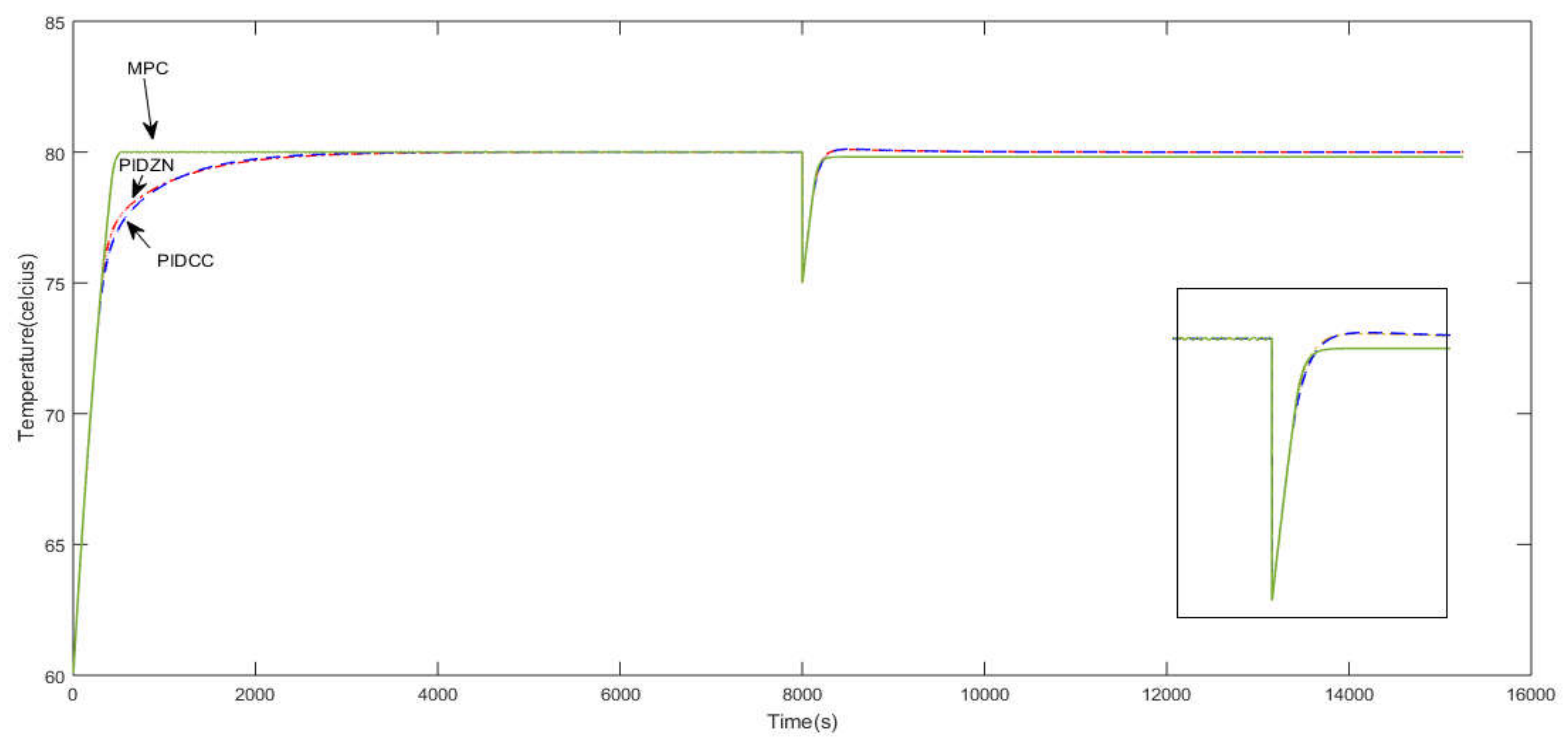

Fig.11. Performance controller for load disturbance

Table 4. Performance of controller for load disturbance test

\begin{tabular}{cc}
\hline Controller & Time Recovering (Seconds) \\
\hline PIDZN & 324 \\
PIDCC & 310 \\
MPC & 289 \\
${ }^{*}$ The highlighted boxes shows best response
\end{tabular}

Fig.11 depicts the controller performance for load disturbance. This test have been done in order to determine how fast the response to recover back to the set point. Therefore, the intended for this test is to test the robustness of those controllers. In this study, the load disturbance been injected at 8000 s. From Table IV, it clearly indicate that MPC have faster 
time recovering compared to PID controller which the difference value are $35 \mathrm{~s}$ and $21 \mathrm{~s}$ for PIDZN and PIDCC respectively.

\section{CONCLUSION}

The hydro distillation process has successful be modelled by using linear ARX modal. The model then been extended for application in designing the controller. In this study, three types of performance test have been done to test the robustness of each controllers. From the comparative analysis, it distinctly shows that both PID controller [31] has poor performances that gave large percentage of overshoot and low accuracy in term of steady state response. In the other hand, almost of MPC scheme provides better performance on overall performance test. Therefore, in overall, it can be concluded that MPC have ability in trajectory the future response. Furthermore, MPC also able in handling the load disturbance and in parameter changes.

\section{ACKNOWLEDGEMENTS}

The authors would like to express the gratitude to Faculty of Electrical Engineering, JPbSM of UiTM Shah Alam, SLAB/SLAI Kementerian Pendidikan Tinggi Malaysia scholarship and also LESTARI Grant no (600-IRMI/DANA 5/3/ LESTARI (0172/2016) for providing the research facility and financial support throughout this research.

\section{REFERENCES}

[1] Jawdat D, Al-Faoury H, Odeh A, Al-Rayan R, Al-Safadi B. Essential oil profiling in callus of some wild and cultivated Daucus genotypes. Industrial Crops and Products, 2016, 94:848-855

[2] Aissi O, Boussaid M, Messaoud C. Essential oil composition in natural populations of Pistacia lentiscus L. from Tunisia: Effect of ecological factors and incidence on antioxidant and antiacetylcholinesterase activities. Industrial Crops and Products, 2016, 91:56-65

[3] Marzaki M H, Tajjudin M, Adnan R, Rahiman M H, Jalil M H. Comparison of different model structure selection using R 2, MDL and AIC criterion. In IEEE 4th Control and System Graduate Research Colloquium, 2013, pp. 80-85 
[4] Dima C, Dima S. Essential oils in foods: Extraction, stabilization, and toxicity. Current Opinion in Food Science, 2015, 5:29-35

[5] El Asbahani A, Miladi K, Badri W, Sala M, Addi E A, Casabianca H, El Mousadik A, Hartmann D, Jilale A, Renaud F N, Elaissari A. Essential oils: From extraction to encapsulation. International Journal of Pharmaceutics, 2015, 483(1):220-243

[6] Yusoff Z M, Muhammad Z, Nordin M N, Rahiman M H, Taib M N. Real time PID control for hydro-diffusion steam distillation essential oil extraction system using Gradient Descent tuning method. In IEEE Control and System Graduate Research Colloquium, 2012, pp. 288-293

[7] Muhammad Z, Rahiman M H, Taib M N. Characteristic of steam distillation pot with induction heating system based on step test response. In IEEE Control and System Graduate Research Colloquium, 2011, pp. 98-102

[8] Yusoff Z M, Muhammad Z, Taib M N, Rahiman M H. Steam temperature control of hydro-diffusion essential oil extraction system using hybrid-fuzzy plus PID controller. In IEEE Conference on Systems, Process and Control, 2014, pp. 105-110

[9] Muhammad Z, Yusoff Z M, Rahiman M H, Taib M N. Modeling of steam distillation pot with ARX model. In IEEE 8th International Colloquium oSignal Processing and its Applications, 2012, pp. 194-198

[10] Samadi M, Abidin Z Z, Yunus R, Biak D R, Yoshida H, Lok E H. Assessing the kinetic model of hydro-distillation and chemical composition of Aquilaria malaccensis leaves essential oil. Chinese Journal of Chemical Engineering, 2017, 25(2):216-222

[11] Awadz F, Yassin I M, Rahiman M H, Taib M N, Zabidi A, Hassan H A. System identification of essential oil extraction system using Non-Linear Autoregressive Model with Exogenous Inputs (NARX). In IEEE Control and System Graduate Research Colloquium. 2010, pp. 20-25

[12] Shariff H M, Marzaki M H, Tajjudin M, Rahiman M H. System identification for steam distillation pilot plant: Comparison between linear and nonlinear models. In IEEE 3rd International Conference on System Engineering and Technology, 2013, pp. 263-268 
[13] Albalasie A, Seliger G, Hanieh A A. Using adaptive model predictive technique to control underactuated robot and minimize energy consumption. Procedia CIRP, 2016, 40:407-412

[14] Zarghami M, Fakharian A, Poudeh A G, Adhami-Mirhosseini A. Model-based predictive control of wheeled omni-directional robots considering nonlinear dynamical constraints and input delay. In 13th IEEE International Conference on Control Automation Robotics and Vision, 2014, pp. 1379-1385

[15] Zhu M, Chen H, Xiong G. A model predictive speed tracking control approach for autonomous ground vehicles. Mechanical Systems and Signal Processing, 2017, 87:138-152 [16] Mosaffa H, Fakharian A. Temperature control of distillation column in Hydro-alkylation of toluene: A supervisory predictive approach. In 4th IEEE International Conference on Control, Instrumentation, and Automation, 2016, pp. 401-406

[17] Seban L, Boruah N, Roy B K. Modified single layer economic model predictive control and application to shell and tube heat exchanger. IFAC-PapersOnLine, 2016, 49(1):754-759 [18] Ratnakumari U V, Triven M B. Implementation of adaptive model predictive controller and model predictive control for temperature regulation and concentration tracking of CSTR. In IEEE International Conference on Communication and Electronics Systems, 2016, pp. 1-6 [19] Damiran U, Fu C, Tan W. Model predictive control of nonlinear drum boiler. In 11th IEEE International Forum on Strategic Technology, 2016, pp. 544-548

[20] Raziei S A, Jiang Z. Model predictive control for complex dynamic systems. In IEEE National Aerospace and Electronics Conference and Ohio Innovation Summit, 2016, pp. 193-200

[21] Mosaffa H, Fakharian A. Temperature control of distillation column in Hydro-alkylation of toluene: A supervisory predictive approach. In 4th IEEE International Conference on Control, Instrumentation, and Automation, 2016, pp. 401-406

[22] Huang B, Gu Y, Su H. Experience-based identification and model predictive control for a methanol recovery distillation column. In 9th IEEE Asian Control Conference, 2013, pp. 1-4 
[23] Assandri A D, de Prada C, Rueda A, Martínez J L. Nonlinear parametric predictive temperature control of a distillation column. Control Engineering Practice. 2013, 21(12):1795-1806

[24] Bagheri P, Ali P B, Sedigh A K, Sedigh K. Analytical approach to tuning of model predictive control for first-order plus dead time models. IET Control Theory and Applications, 2013, 7(14):1806-1817

[25] Tajjudin N, Ismail N, Rahiman M F, Taib M N. Model predictive control using ARX model for steam distillation essential oil extraction system. In IEEE International Conference on Intelligent and Advanced Systems, 2010, pp. 1-5

[26] Marzaki M H, Jalil M H, Shariff H M, Adnan R, Rahiman M H. Comparative study of Model Predictive Controller (MPC) and PID Controller on regulation temperature for SSISD plant. In IEEE 5th Control and System Graduate Research Colloquium, 2014, pp. 136-140

[27] Sharma N, Singh K. Model predictive control and neural network predictive control of TAME reactive distillation column. Chemical Engineering and Processing: Process Intensification, 2012, 59:9-21

[28] Bagyaveereswaran V, Mathur T D, Gupta S, Arulmozhivarman P. Performance comparison of next generation controller and MPC in real time for a SISO process with low cost DAQ unit. Alexandria Engineering Journal, 2016, 55(3):2515-2524

[29] Anucha S, Chayavivatkul V, Banjerdpongchai D. Comparison of PID control and linear model predictive control application to regenerative thermal oxidizer system. In 10th IEEE Asian Control Conference, 2015, pp. 1-5

[30] Ozen O, Sariyildiz E, Yu H, Ogawa K, Ohnishi K, Sabanovic A. Practical PID controller tuning for motion control. In IEEE International Conference on Mechatronics, 2015, pp. 240-245

[31] Nawi B, Sulaini B, Mohd Z A R, Shamsul A Z, Zairi I R. PID voltage control for DC motor using MATLAB Simulink and Arduino microcontroller. Journal of Applied Environmental and Biological Sciences, 2015, 5(9):166-173

[32] Zabidi A, Tahir N M, Yassin I M, Rizman Z I. The performance of binary artificial bee colony (BABC) in structure selection of polynomial NARX and NARMAX models. 
International Journal on Advanced Science, Engineering and Information Technology. 2017, $7(2): 373-379$

[33] Yassin I M, Jailani R, Ali M, Baharom R, Hassan A, Rizman Z I. Comparison between cascade forward and multi-layer perceptron neural networks for NARX functional electrical stimulation (FES)-based muscle model. International Journal on Advanced Science, Engineering and Information Technology, 2017, 7(1):215-221

\section{How to cite this article:}

Mohammad NN, Azman A A, Marzaki MH, Adnan R, Ismail N, Rahiman MHF.Comparison between mpc and pid control for compact hydro distillation process. J. Fundam. Appl. Sci., 2017, 9(4S), 77-93. 